12

\title{
Экспериментальное исследование распределений плотности тока технологического электронного пучка
}

\author{
(C) А.В. Щербаков, Р.В. Родякина, А.С. Кожеченко, \\ Д.А. Гапонова, А.Л. Гончаров, В.К. Драгунов
}

Национальный исследовательский университет „МЭИ“, Москва

E-mail: ShcherbakovAV@mpei.ru

Поступило в Редакцию 13 июня 2017 г.

Предложена экспериментальная методика получения распределений плотности тока непрерывно действующих электронных пучков с энергией электронов $60 \mathrm{keV}$. Приведены результаты измерений для различных поперечных сечений пучка мощностью $2.1 \mathrm{~kW}$ с плотностью тока порядка $1 \cdot 10^{5} \mathrm{~A} / \mathrm{m}^{2}$.

DOI: 10.21883/PJTF.2017.21.45156.16916

При разработке электронных пушек, формирующих непрерывно действующие пучки с энергиями $20-100 \mathrm{keV}$ и токами $0.01-0.1 \mathrm{~A}$, возникает необходимость измерения пространственных распределений плотности тока [1], что нужно для верификации результатов расчета электронно-оптических систем. Поскольку пушки с указанными характеристиками применяются главным образом для технологических целей, измерение характеристик пучков в них также необходимо для обеспечения воспроизводимости технологических режимов и „переноса технологии“ с одной установки на другую [2].

Для решения поставленной задачи можно использовать различные экспериментальные методы [3]. Прямые методы [1,2,4,5] основаны на непосредственном измерении составляющих тока, протекающих через коллекторы из электропроводных материалов, при сканировании луча или перемещении датчика. Они применимы для пучков ограниченной плотности с размерами, превышающими размеры зонда (коллектора, щели). Косвенные методы предполагают измерение излучений, полей и потоков частиц, формируемых в окружающем пучок пространстве при его прохождении сквозь различные среды [6-9]. Они могут быть использованы для регистрации сколь угодно мощных пучков, однако из-за 


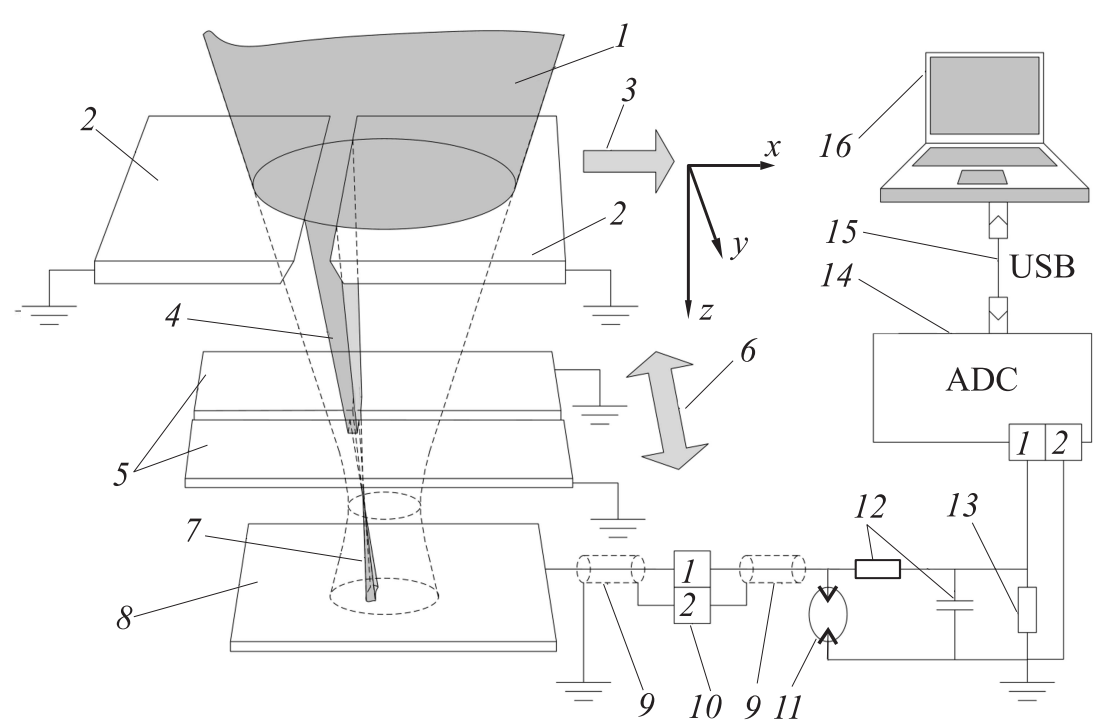

Pис. 1. Схема эксперимента: 1 - электронный пучок, 2,3 - первая диафрагма (молибден) и направление ее движения, 4 - пучок, ограниченный первой диафрагмой, 5, 6 - вторая диафрагма (медь) и направление ее движения, 7 пучок, ограниченный второй диафрагмой, 8 - коллектор (медь), 9 - экранированный кабель, 10 - вакуумный разъем, $11-$ разрядник, $12-\mathrm{RC}$-фильтр, 13 - измерительный резистор, 14 - аналогово-цифровой преобразователь, 15 - кабель USB, 16 - компьютер.

нелинейной связи фиксируемых величин с плотностью тока, а также их пространственной и временно́й дисперсии не позволяют с приемлемой для нашей задачи точностью регистрировать распределения плотности тока частиц пучка.

Ввиду того что исследуемые пучки характеризуются углами сходимости порядка единиц градусов $[1,4]$, был сделан вывод о возможности использования прямого метода, являющегося вариацией метода отсекающей диафрагмы [3], при исключении необходимости отклонения пучка как фактора, влияющего на пространственные характеристики. Основной идеей метода, реализованного на экспериментальной установке с пушкой ЭЛА-15И, является использование двух щелевых диафрагм

Письма в ЖТФ, 2017, том 43, вып. 21 
(рис. 1). Первая диафрагма, принимающая бо́льшую часть энергии пучка, расположена в расфокусированной части пучка значительно выше второй, в плоскости которой проводятся измерения. Первая диафрагма перемещалась вдоль оси $x$ с шагом $0.5 \mathrm{~mm}$ на общее расстояние $20 \mathrm{~mm}$, а вторая перемещалась бесступенчато в диапазоне $\pm 10 \mathrm{~mm}$ от оси пучка вдоль оси $y$. Сбор данных осуществлялся с частотой выборок $100 \mathrm{kHz}$ при скорости поступательного перемещения диафрагм $0.015 \mathrm{~m} / \mathrm{s}$.

Первоначально неподвижный пучок фокусировался на массивной медной мишени, установленной по высоте на уровне второй диафрагмы, по критерию максимальной яркости свечения плазменного факела. Затем фокусировка корректировалась для установления максимального сжатия зондовой кривой. В результате коррекции ток магнитной фокусирующей катушки для всех проводимых экспериментов составлял $745 \mathrm{~mA}$. Координаты оси пучка определялись при токе $5 \mathrm{~mA}$ по максимуму регистрируемого сигнала коллектора при поочередном перемещении обеих диафрагм вдоль осей $x$ и $y$. Общее время измерения для получения 40 распределений вдоль одной оси с шагом перемещения первой диафрагмы $0.5 \mathrm{~mm}$ составляло $55 \mathrm{~s}$. Временно́й интервал между измерениями составлял $15 \mathrm{~min}$, что было необходимо для охлаждения датчика.

Результаты измерений показаны на рис. 2. Для удобства восприятия регистрируемые напряжения показаны изменяющимися в положительную сторону относительно корпуса установки. Число регистрируемых распределений определялось размерами пучка вдоль оси $x$ и составляло для случая, показанного на рис. $2, a,-19$, а для случаев, представленных на рис. $2, b$ и $c,-14$ и 12 соответственно. Представленные на рис. 2 кривые могут быть отображены в единицах плотности тока $\left(\mathrm{A} / \mathrm{m}^{2}\right)$. Поскольку точный координатный шаг вдоль оси $x$ между регистрируемыми кривыми не был известен, все измерения необходимо было повторить в поперечном направлении. После совмещения полученных распределений в пространстве координат $x$ и $y$ было установлено, что максимум распределения на рис. $2, c$ соответствует плотности тока $0.15 \mathrm{~A} / \mathrm{mm}^{2}$.

При положении плоскости измерения выше плоскости наилучшей фокусировки радиальное распределение плотности тока пучка имеет четкий минимум в центре. Напротив, в плоскости наилучшей фокусировки максимум плотности тока наблюдается на оси пучка, а в периферийной части плотность тока значительно выше, чем следовало бы 

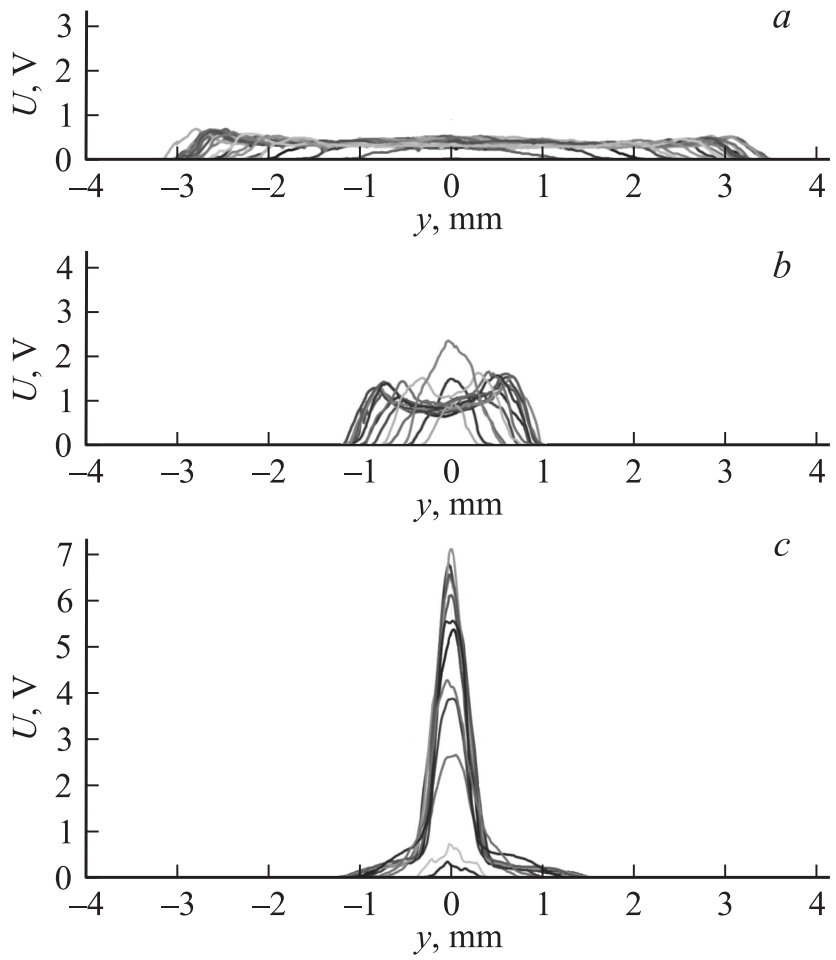

Рис. 2. Экспериментальные зависимости напряжения на коллекторе от линейной координаты $y$ при различных положениях плоскости измерения: $a-$ на $135 \mathrm{~mm}$ выше плоскости фокуса, $b-$ на $35 \mathrm{~mm}$ выше плоскости фокуса, $c-$ в плоскости фокуса.

ожидать при нормальном (гауссовом) распределении. Кроме того, пучок имеет четко очерченные границы, радиальная зависимость плотности тока резко обрывается (рис. 2, c). В плоскости, расположенной на $35 \mathrm{~mm}$ ниже плоскости наилучшей фокусировки (на рис. 2 этот случай не показан), плотность тока в периферийной части растет, а в центральной, напротив, уменьшается. Все описанные особенности пространственных распределений плотности тока связаны с нелинейной характеристикой поперечного эмиттанса пучка и обусловлены несовпадением главных

Письма в ЖТФ, 2017, том 43, вып. 21 
фокусов для траекторий частиц, движущихся на разных расстояниях от оптической оси электронной пушки.

При исследовании мощных электронных пучков необходимо учитывать влияние коллекторной плазмы, возникающей в результате ионизации десорбированного газа и диэлектрических пленок, осажденных на поверхности коллектора [10], или паров материала коллектора, на измеряемые зондовые характеристики из-за возникновения неконтролируемых контуров протекания токов, обусловленных проводимостью плазмы, и переходных процессов в цепях измерения. В нашем случае малые размеры пучка обусловили возможность изготовления пластин коллектора и диафрагм с размерами, намного превышающими размеры самого пучка (размеры верхней диафрагмы $100 \times 100 \mathrm{~mm}$ ). Боковые заземленные или экранирующие стенки, которые могли бы исказить регистрируемые сигналы, у датчика отсутствуют. Поэтому, учитывая, что пучок действует непрерывно, условия формирования плазмы вблизи диафрагм и коллектора датчика можно считать не меняющимися при сканировании и зависящими только от самой плотности тока пучка. Влиянием динамики плазменных процессов на регистрируемые сигналы можно пренебречь, поскольку время записи одного линейного распределения на три-четыре порядка превышает время переходных процессов в плазме и составляет от 0.05 до $0.5 \mathrm{~s}$. Отсюда можно сделать вывод о том, что качественный вид характеристик на рис. 2 в целом будет соответствовать реальным пространственным распределениям плотности тока.

Проведенные исследования подтвердили возможность расширения границ применения (по плотности теплового потока) зондовых методов измерения характеристик мощных непрерывно действующих электронных пучков. Анализ результатов измерения пространственных распределений электронного пучка с энергией $60 \mathrm{keV}$ и током $35 \mathrm{~mA}$ показал, что максимальная плотность тока в пучке достигает $0.15 \mathrm{~A} / \mathrm{mm}^{2}$. Было выявлено существенное отличие регистрируемых распределений плотности тока от традиционно принимаемого в расчетах закона нормального распределения, в том числе и в плоскости наилучшей фокусировки, где присутствует резко обрывающаяся периферийная область, а также отклонения от осевой симметрии. Эти результаты имеют важное значение и могут быть использованы для исследования процессов формирования мощных электронных пучков, в том числе при возникновении аберраций различного типа.

Письма в ЖТФ, 2017, том 43, вып. 21 
Работа выполнена в ФГБОУ ВО НИУ „МЭИ“ при финансовой поддержке Министерства образования и науки РФ в рамках выполнения базовой части госзадания (проект № 11.8088.2017/8.9).

\section{Список литературы}

[1] Корнилов С.Ю., Ремпе Н.Г., Beniash А. // Письма в ЖТФ. 2013. Т. 39. В. 12. C. 1-8.

[2] Elmer J.W., Teruya A.T. // Welding J. 2001. V. 80. P. 288-295.

[3] Смалюк В.В. Диагностика пучков заряженных частиц в ускорителях / Под ред. Н.С. Диканского. Новосибирск: Параллель, 2009. 294 с.

[4] Koleva E., Mladenov G., Todorov D., Koleva L., Kardjiev M. // J. Phys.: Conf. Ser. 2016. V. 700. P. 1-9.

[5] Зенин А.А., Бакеев И.Ю., Бурачевский Ю.А., Климов А.С., Окс Е.М. // Письма в ЖТФ. 2016. Т. 42. В. 13. С. 104-110.

[6] Шарафутдинов А.Ф., Науменко Г.А., Потылицин А.П. и др. // Изв. Томск. политехн. ун-та. 2004. № 2. С. 15-19.

[7] Бочаров А.Н., Мурыгин А.В. // Вестн. СибГАУ. 2005. № 3. С. 191-195.

[8] Воробьев М.С., Коваль Н.Н. // Письма в ЖТФ. 2016. Т. 42. В. 11. С. 41-47.

[9] Логачев П.В., Мешков О.И., Старостенко А.А. и др. // Физика элементарных частиц и атомного ядра. 2016. Т. 47. В. 2. С. 443-500.

[10] Воробьев М.С., Девятков В.Н., Коваль Н.Н., Сулакшин С.А. // Плазменная эмиссионная электроника. Улан-Удэ: Изд-во БНЦ СО РАН, 2015. С. 163170. 